\title{
The Uncommons: An Introduction
}

\author{
Mario Blaser Memorial University \\ Marisol de la Cadena University of California, Davis
}

\begin{abstract}
This article introduces the term uncommons as a conceptual response to questions that emerged in the context of conflicts around the scale and scope of diverse "commons" that are under threat by extractivism. It introduces the articles for this special issue, which were the result of an invitation to think with the concept of uncommons for a variety of situations. It is concluded that these articles provide a strong grounding to think of uncommons as constitutive of the commons, and that "uncommoning" might be crucial for giving shape to solid commons.
\end{abstract}

Keywords: commons, commoning, uncommons, extractivism, equivocation, conflict, development, environment

Résumé : Dans cet article, le terme «incommun » est présenté comme une réponse conceptuelle à des questions soulevées dans un contexte de conflits entourant l'échelle et l'étendue de plusieurs « communs » menacés par l'extractivisme. Il présente les articles de ce numéro spécial, soumis en réponse à l'invitation à réfléchir sur le concept des « incommuns » dans des situations variées. Il conclut que ces articles constituent un fort ancrage suggérant que les incommuns sont constitutifs des communs et que le " faire incommun » pourrait être crucial dans la constitution de communs solides.

Mots-clés : communs, faire commun, anticommuns, extractivisme, équivocation, conflit, développement, environnement
The idea of "the uncommons" imposed itself on us (the guest editors) in the context of our experience of a very specific moment in South America, when the socio-environmental conflicts that have accompanied the consolidation of neo-extractivism became increasingly visible. Neo-extractivism is a model of development primarily based in the large-scale extraction of natural resources for export (see Acosta 2010; Gudynas 2011). This model has taken form under both conservative and progressive governments, with the former continuing and deepening previous trends of privatisation of revenues generated by exports, while the latter, tending to use those revenues to reduce poverty, increase social participation and ensure their own political stability (see Burchardt and Dietz 2014). The paradigmatic figures of neo-extractivism are strip mining, the expansion of carbon fuels frontiers, the building of large hydroelectric dams, and the generalisation of large-scale agribusiness models. Given that these activities often involve the destruction and/or enclosure of "commons," it is not surprising to see neo-extractivist governments depicting them as "common goods" to be appropriated by corporations, or the state, in pursuit of the national "common good." Not surprisingly, invocations of the common good have not deterred the emergence of grassroots - though not necessarily simply local - opposition to these designs; rather, conflicts that variously highlight the environmental and social consequences of the destruction of the commons have become endemic wherever extractivist projects are planned or implemented (see Svampa 2015).

What captured our attention in this context was twofold: First, was the paradoxical conceptual convergence between extractivist governments' justifications for the enclosure of commons for the greater common good and environmental and social justice justifications for a defence of the commons. Second, was that this paradoxical convergence threw into sharp relief the limits of the terms with which these conflicts were being discussed. Even though "enclosures" and "the commons" 
have been written into political economy analysis as opposite to each other - with the former destroying the latter as capitalism unfolded, but with the possibility of eventually turning the tide in the other direction - both concepts, articulated through a series of cascading binaries (such as individual and collective, private and public, basic subsistence and profit), end up converging. This convergence is on the underlying assumed ontological continuity among humans and ontological discontinuity between humans and non-humans. These are assumptions that enable a relation that objectifies non-humans as natural resources, the distribution, access and use of which can then become a point of contention among human subjects.

This conceptual convergence stands in stark contrast with expressions we heard from our interlocutors, who indicated that what mobilised them was not only an interest in preserving their commons but also a feeling of obligation (charged with trepidation about the potential consequences of not fulfilling it) toward what we would call forests, animals, rivers and mountains, which they described as powerful other-than-human persons (see Blaser 2013a, 2013b; de la Cadena 2010, 2015). What our interlocutors were saying brought forward something that exceeded the analytical purchase of concepts based on the ontological discontinuity between humans and non-humans but without, in practice, ceasing to be entangled with those concepts. For example, otherthan-human persons are presented (by our interlocutors, their allies, opponents and commentators) through the languages of religion (such as a sacred mountain) or culture (such as so-called traditional beliefs) that translate the excess into hegemonic forms of recognition.

We speculated that what John Law $(2015,127)$ calls the "one-world world" - that is, the assumption that the world "is really something like a large space-time box that goes on by itself. And ... that there are people with different beliefs living in this space-time box" - is partially enacted by these kinds of colonial processes, whereby heterogeneous assemblages of life that do not necessarily make themselves using the division between humans and non-humans (nor do they necessarily enact themselves through such entities only) are both obliged into that distinction and continue to exist exceeding it. We conceptualised this entangled excess as "the uncommons," a condition that disrupts (yet does not replace) the idea of "the world" as shared ground: an idea that appears as the condition of possibility for the common good and of commons.

In recent years, there has been a vigorous critique of the idea of the commons as simply being a common pool of resources (compare with Ostrom 2015). As Linebaugh $(2008,279)$ puts it,

To speak of the commons as if it were a natural resource is misleading at best and dangerous at worst the commons is an activity and, if anything, it expresses relationships in society that are inseparable from relations to nature. It might be better to keep the word as a verb, an activity, rather than as a noun, a substantive.

In these discussions, authors prefer to speak of "commoning," a process of creating and nurturing community (see Bollier and Helfrich 2014, 2015) that for some authors includes non-humans as active agents (Papadopoulos 2010). With different intensity, and without always overcoming it, these emerging theorisations take distance from the ontological discontinuity between humans and non-humans that enables the latter's conversion into resources that can be conceptually (and practically) delinked from the human communities that use, reproduce and depend on them. In other words, the commons are conceived here as ongoing, always in the making, indissoluble wholes of human and nonhumans. As the saying in commons' circles goes, there is "no commons without community."

But what does commoning, the making of these "wholes," entail? For Federici (2014, 228-229), "if commoning has any meaning, it must be the production of ourselves as a common subject." This is how we must understand the slogan "no commons without community." She further clarifies that her idea of community refers to "a quality of relations, a principle of cooperation and of responsibility to each other and to the earth, the forests, the seas, the animals," rather than to "a grouping of people joined by exclusive interests separating them from others" (Federici 2014, 229). Yet the idea of community denotes a shared domain, which, in light of our perception of uncommonalities, begs questions of scale, scope and relations: How far does the shared domain that constitutes a community extend? What kinds of things does it include, and what kinds of responsibilities do these things demand? What are the possible relations between the commons and the uncommons? In short, the idea of the commons and of commoning call forth an exploration of what making "things" (objects, identities, concepts, ideas and so on) common implies, especially where things might (also) be uncommon. The articles gathered here respond to an invitation to carry on such exploration. ${ }^{1}$ In what follows, we present them along three axes following the questions above about scale, scope and relations. 


\section{(Un)Commoning Scales}

Even if they might be merely rhetorical, governmental appeals to the national common good to justify the seizing of commons have some purchase, because they connect with an issue that is never quite settled. That issue is, at what scale should the boundary of a commons (and its associated community) be drawn? Which community associated with a common, such as a river, should decide how to use and treat it? Should it be the communities that live on the river's banks, the citizenry of the country it traverses, or the global community that cares for the role of the river in planetary systems? An important part of the commons literature, which operates with the conventional scalar imagination of nested units according to which large-scale domains encompass smaller ones (that is, the global encompasses the national that encompasses the regional that encompasses the local), normatively addresses the potential conflict between scales with more or less "sliding" versions of the subsidiarity principle. This is the idea that decisions should be delegated to the smallest jurisdictional unit able to handle them in benefit of the commons, unless doing so might generate conflict between "units"; in such a case, decision making should be "passed up" to a higher level unit (see Fennell 2011; Marshall 2007; Ostrom 2009). Yet, as Casper Bruun Jensen's contribution to this issue makes evident, there seems to be an unanalysed scale problem at work in these discussions: when looked at closely, the relations between scales involve not only potential conflicts but also a proliferation of uncommons.

Jensen contrasts the conventional meaning of the commons as a set of resources equally accessible to everyone with their own "shared presuppositions of what practices or worlds consist of." However, if we consider arguments about commoning mentioned previously, the contrast between the two meanings seems less sharp, insofar as commoning unavoidably entails outlining a shared domain. Looking at the commons through the practices of "domaining," Jensen argues, enables us to see them as projects or designs that need to be constantly realised, for they are not a given. For example, a river like the Mekong might be domained as a common source of livelihood by riverine communities, as a (potential) common source of hydroelectric energy by the governments putatively representing citizens of a country it traverses, and as a key component of the biodiversity commons by transnational environmental organisations. If we keep in sight that the river is a source of livelihood, a potential energy source, or a repository of biodiversity, we can see that each constitutes different projects of domaining (or commoning), and it is easier to grasp the idea that their scales might be an effect of how such projects are pursued.

As Jensen argues, contrary to what the conventional scalar imagination would have us expect, small-scale commons are not nested into larger ones until they constitute a "whole" common. In fact, the commons come into existence, or they become large or small, depending on how domains relate to each other. As becomes evident in Jensen's examples, to establish itself as a common global concern, the preservation of a biodiversity common might need to be linked to the common source of livelihood of riverine communities through projects such as forestry and ecotourism, which might ease the use of the river for fishing. Conversely, embattled communities' livelihoods might gain substance by engaging available projects to protect global biodiversity such as forestry and ecotourism, thereby becoming a "local" version of a "global commons." One of the crucial points that Jensen drives home, however, is that regardless of whether the scale is large or small, domains constitute sites where uncommonalities abound. A forestry project, for example, might appear as a (small-scale) common domain involving local villagers and national and transnational NGOs, but the commonality does not run very deep. While local villagers might hope to deter logging or the encroachment of plantations or to draw resources from the project for their own purposes (including perhaps making offers to spirits), the national NGO is interested in livelihood improvement, and the transnational NGO is concerned with biodiversity. Since commoning (or domaining) has to be constantly performed, not least by aligning different domaining projects, the uncommons constantly proliferates. To put it otherwise, it would seem as if the uncommons is constitutive of the commons.

A similar point is argued by Judith Farquhar, Lili Lai and Marshall Kramer in their "yin-yang geography" of Bijiang. These authors understand the commons primarily as a shared domain, albeit, in their case, a domain characterised as a "known universe" produced by the activities of the Chinese state. This commons is generated through the extension of the state as it "scales up" its version of a knowable and properly ordered form of relation between humans and non-humans.

The geographical area where the authors ground their reflection is roughly the same as the one in which James Scott based his own reflection on the reach of the state and the "spaces of freedom" that might escape from it. In contrast to such a trope, the authors liken the state's ordering of its geography (in the sense of rendering spaces knowable) to the illuminating brightness of the yang principle; thus, as the yang has a yin, the knowable commons produced by the state also engenders the 
uncommons - that which exceeds it and cannot be articulated by it. The important contrast with Scott is that the relation between the state's reach (its tracing of the commons) and that which it cannot reach (the uncommons) is not one of exteriority, but rather one of mutual interiority; the commons and the uncommons give meaning to each other and, as importantly, they incite each other as active principles, thus producing an oscillation that takes place in time. The activities of the state that yesterday sought to transform a remote village in the mountains into an ordered and knowable city is nowadays the soil from which "wild" entities (like weeds) and behaviours (like drunken parties in the vault of an abandoned bank) grow. Intriguingly, these very uncommon traits might be the ground that incites a new round of ordering activity.

In stressing the mutual interiority and the temporality of the relation (the oscillation) between the commons and the uncommons, Farquhar, Lai and Kramer's article emphasises a key point we want to stress: that the uncommons must not be conceptualised as an expression of pre-existing fossilised differences (that is, a bunch of practices or "things" that have always already been there as the same to themselves and different from each other) but rather as an ongoing and everchanging process of divergence. To return to Jensen's examples, spirits feasting today with resources from a forestry project is not exactly the same as feasting was done in the past, and yet engaging a forestry project partly to draw on these resources for feasting spirits is different from engaging it to protect biodiversity. In other words, that new relations between domains (for example, "feasting spirits" and "biodiversity conservation"), enabled by the formation of a new domain (for example, the forestry project), might change the former (that is, make them diverge from themselves) does not mean that they converge, becoming the same. One could say that without them being unchanging, each domain brings its own uncommon "things" to a process of commoning.

\section{(Un)Commoning Scope}

What Law calls the one-world world (OWW) (2015) might be thought of as a large-scale (universal) project of commoning, understood as the making of one shared domain within which all differences exist. Of course, what Jensen says about the making of domains applies to this universal domain: its making is an effect of practices that assume the domain already exists. However, the plausibility of these assumptions rests on the successful work that assembles the domain in question. Global biodiversity is a plausible domain insofar as a variety of local versions of it are successfully linked with each other. The well-worn but no less illustrative Latourian example of the railway system is apposite here. Such a "global" system can be said to exist only to the extent that "localised" stations, tracks, signals and ticket collectors connect to each other and hold together. Connections and linkages are obviously central to the constitution of domains (or commons), but no less central is whether uncommon things might be pliable enough to hold together, thus delimiting the possible scope of a commons. An important question then is, under what conditions might the uncommons sustain the commons?

In his contribution to the issue, Atsuro Morita looks at a particular moment in the history of the making of the OWW, when the universal commonality of "nature" was being established through the extension of scientific practices across a multiplicity of geographic locales. His anchoring example is the encounter of the Humboldtian project to generate a "comprehensive portrait of the universe" and King Mongkut of Siam's enrolment in such a project (or some aspects of it) for his own ends. The paradigmatic event is an expedition to the jungle organised by the king to witness a full solar eclipse, which he had predicted. Morita tells us that the expedition brought together "the Siamese royal family, nobles, eminent court astrologers, French astronomers, diplomats from various European countries ... the governor of Singapore," and, of course, "instruments for astronomical observation." One could interpret this event as an extension of scientific practices that lends further credibility to Humboldt's assumption of a universe ordered in a particular way and composed by specific "things" and laws to be studied according to a specific method. Such interpretation would not be wrong, but what Morita shows is that there was also something else to it: the king's attempt to manage the relation between Siam and colonial powers, informed by Siamese "common" knowledge about how a universe of "thousand-cubed great thousands worlds" must be held together!

The king's actions were consonant with the governance of "a mandala polity" that, in following Hindu-Buddhist cosmological arrangements, was conceived as a series of concentric circles of influence and power amidst a multiplicity of similarly configured polities. Astrology played a central role among the political and diplomatic technologies of mandalas, and astronomy and geodesy were taken up by the king in that vein. This must not be seen as the king simply incorporating some elements of scientific practices into traditional astrology and political management, however. In a similar fashion to our example of forestry described in the previous section, the king was giving shape to a new domain within what the 
author calls an interstitial space, "[a space] between various practices of knowing and managing the world." The practices that took shape in this domain simultaneously diverged from and connected with their "roots" (for example, astrology, astronomy, geodesy or diplomacy). They diverged from their roots because they were woven into a new assemblage of practices, yet they connected with their roots because they could be perfectly recognised as pertaining to established protocols. The simultaneous connection and divergence of the king's practices from their roots eventually enabled scientists to see the expedition as representing "the victory of modern science and the enlightened monarch over superstition," and enabled Thai astrologers and their clients to see it "as marking the beginning of modern Thai astrology." In other words, the commoning or domaining done by the king in the interstitial space could only tenuously efface the uncommonality upon which it was based. And yet, for however long it lasted, and in part because it constituted a field of equivocations, this new domain allowed modern science and Thai astrology to stand in common, even if diverging.

As hinted at above, it seems that equivocations play a key role in holding the uncommons together as a commons. Equivocations - a notion we borrow from Eduardo Viveiros de Castro (2004) - take place when there is a failure to understand that while using the same term, interlocutors are referring to different things. The domain of common practices delineated by the king of Siam constituted a field of equivocations in the sense that the practices performed during the expedition had different referents for different interlocutors: For scientists, the practices referred to the universal order of the Humboldtian cosmos; for Thai astrologers, they referred to the universal order of the thousand-cubed great thousands worlds. One could imagine these interlocutors congratulating each other on the success of the expedition without realising they were referring to different things, a homonymic set of practices with different referents.

In her contribution to the special issue, Margaret Wiener focuses on two sets of practices related to "things" that also operate as fields of equivocation: kris and territory. The former are Indonesian heirloom daggers that gather a host of uncommoning practices, such as "museological practices aimed at preserving an object's material integrity and Balinese rites aimed at empowerment" of the daggers as powerful and active more-than-humans. Wiener shows how these uncommon practices constantly simmer just under the surface of the (assumed) common world of material objects but also how they intermittently flare up, becoming visible. A conversation with a curator from Indonesia's National Museum reveals that her curatorial practices also involve enrolling ritual experts to ensure that heirlooms "would enact their expected museum role as inert objects" rather than erupting as potent actors. Uncommonalities also flare up during a tour of these national heirlooms from the National Museum in Jakarta to the Klungkung regency in Bali for a state commemoration. The visit of the heirlooms constitutes another field of equivocations, where a state commemoration and a Balinese ritual run parallel to and overlap with each other, the uncommonality becoming fleetingly visible when the heirlooms are not engaged exactly as the protocols of museological preservation or ritual handling prescribe. This visible fleetingness occurs, for example, when the "museum objects" are manipulated by a priest without gloves, as preservation practices would indicate, or when a museum staff member accompanying the heirlooms is concerned about the health hazards of sipping holy water produced through the rites. However, the visibility of the uncommon lasts only so long: a small modification of protocol (ritual handlers cease to touch the heirlooms with bare hands) and a resort to "ecumenical language" (the Muslim museum staff member is told that God has removed all bacteria from the water) bring back the two sets of practices to the terrain of the commons.

This silencing of the uncommons is not always possible. Wiener makes this point more poignantly in her discussion of the uncommoning of an aspect of Bali's territory, its beaches. Beaches, along with ravines and cemeteries, are locations that Balinese call tenget, dangerous or haunted. During a few months in 1965-66, somewhere from 80,000 to 150,000 people died at the hands of anti-Communist paramilitary groups, neighbours and even kin in a spree of Cold War violence launched by General Suharto's New Order regime. Tenget places were where most of the killings took place and where the bodies were buried. Except for cemeteries, these places have great appeal to Euro-Americans, which made them very attractive to investors in the tourist industry, including the politicians and generals that promoted the massacres. An "entire industry was built on top of the bodies of those whose deaths enabled those profiting from it to come to power." However, since the fall of the New Order, a movement to exhume mass graves has been growing. In some cases in Bali, the movement is prompted by the dead themselves, who, through possessions, paranormal sightings and suicides, demand proper cremation. To respond fully to the demands of the dead, however, hotels built upon mass grave sites would need to be removed. Besides the practical problems (not the least circumventing the interests of powerful politicians), the publicity around the issue 
would severely harm an industry upon which many Balinese depend. As Wiener puts it, the situation

brings into view clashes among different forms of ... prosperity, even for the Balinese: those resulting from maintaining proper relations between the living and the dead and between humans and other-thanhuman forces, and those associated with the commoning force known as capitalism.

Side by side, Wiener's two examples bring to the forefront the productivity of equivocations concerning the constitution of the commons: they enable diverging practices to stand together with minimal mutual interruption. It is no surprise then that in some cases, equivocations seem to be actively fostered to keep divergences under the radar, so to speak. In the case of kris, small modifications to ritual protocol or the use of ecumenical language do this job. In a similar fashion, it is likely that the National Museum curator is also guarded about her ritual practices before a professional museology public. But in contrast to the Balinese beaches, where tending to the dead and sustaining a tourist industry decidedly clash against each other, in these two cases, uncommon practices can be kept in a field of equivocations because they do not severely interrupt each other or irremediably disrupt the commoning work. It seems, then, that the uncommons become visible either when practices clash with each other or when the analyst underscores the equivocations upon which a commons might be based. Since commoning seems to have a positive value, what would be the political significance of making the uncommon visible - of uncommoning?

\section{(Un)Commoning Relations}

In the commons literature, commoning has been posed as the antithesis of enclosures. Yet, as David Harvey (2011) points out, a commons implies some degree of enclosure. Neither everyone nor everything comes to be part of a particular commons. Both commoning and enclosures involve domaining, and the domains thus delineated have variable reach and scope. The key difference between commoning and enclosing, then, is the former's orientation toward a more democratic, egalitarian and just constitution of a domain for humans and non-humans: a commons. There is, however, a slippage from the commons as a noun to commoning as an action. As Jensen points out, domains (or commons) take shape as effects of actions (commoning) that assume the preexistence of the domains being built. Thus, participants tend to assume that a given common is exhaustive in relation to the terms whereby it has been constituted. The cases discussed in this issue's articles indicate other- wise. This does not mean that the commons are not effectively constituted by commoning but rather that even when they are, the uncommons are right below the surface. We have argued that equivocations play an important role in successful commoning, but what must not be lost from sight is that more often than not, fields of equivocations are asymmetrical. This implies that the key role that the uncommons play in the constitution of the commons ends up being disavowed, and the latter ends up not living up to its democratic, egalitarian and just promises. Let us examine this point by returning to some of the cases discussed in the articles.

Other than through the author's ethnographic analysis, the only case where the uncommons seems readily visible in the articles is in the clash between proper relations to the dead and tourism as they encounter each other on Balinese beaches. Wiener gives a clear indication of how this flaring up of the uncommons will likely unfold in the near future: tourism will prevail, suffocating the possibilities of proper treatment of the dead. In this example, there is no possibility of a productive equivocation that will make beaches a commons for both sets of practices. The power asymmetry between practices nowadays makes it so that the disagreement is settled univocally. ${ }^{2}$

Now we can turn to a couple of revealing details in the cases of King Mongkut's expedition and the touring kris, in which equivocations made it possible to constitute a commons. Recall that, according to Morita, for scientists, the king's expedition represented "the victory of modern science and the enlightened monarch over superstition," and for Thai astrologers and their clients, "the beginning of modern Thai astrology" (emphasis added). While something changes for Thai astrology (a change marked by its requalification as "modern"), modern science just gets reconfirmed. One feels tempted to say that while Thai astrology sees and takes modern science as knowledge, the reverse is not the case. With the kris, a similar asymmetry is evident, and the work to keep the equivocation functioning is shouldered by those who engage the heirlooms as other-than-human agents. They cover their hands to accommodate museological preservation practices; they resort to "ecumenical language" to appease the concerns of state agents. In other words, in these cases, commoning comes at the cost of subordinating one set of practices to the other through "same-ing" - that is, an equivalence is proclaimed (and accepted) where a divergence is actually operative. The consequence is that dominant practices can eventually operate as if the subordinate ones were irrelevant to the constitution of the commons. Uncommoning runs counter to this possibility, not simply by 
emphasising that practices taken as common are different (that is, the contrary of the same) but rather by stressing that they are divergent, a concept Isabelle Stengers (2005) uses to explain what she calls an "ecology of practices." Accordingly, the practices that interest us are constituted by their own positive divergence as they symbiotically come together - like in an ecological system - while also remaining distinct: what brings them together is an interest in common that is not the same interest. The point of uncommoning, then, is not to preclude the possibility of commoning but rather, whenever possible, to seek ways to base the latter on the more solid grounds of recognised productive divergences.

Amiria Salmond's contribution on recursive ethnography provides elements to think about how these "more solid grounds" can be fostered. Recursive ethnography begins with a simple observation about the ethnographic set-up; the ethnographer confronts "things" that, in comparison, are uncommon to herself and her audience. The challenge is to render this uncommon as common. For the recursive ethnographer, the challenge of rendering the uncommon common is not met by simply generating comprehension in terms already available to the ethnographer (and her audience); instead, the challenge is "how to create an awareness of different social worlds when all at one's disposal is terms which belong to one's own" (Strathern et al. 1987, quoted by Salmond)? Rather than giving up on ethnography because of the impossibility of understanding others on their own terms, recursive approaches

explore this question through methodological experimentation and by investigating what insights and implications (practical, philosophical, political) might be drawn out and opened up through ethnographic transformations - that is, via the ways in which ethnography inevitably alters what it studies while at the same time being transformed ("becoming alter to") itself. (original emphasis)

Salmond exemplifies this recursive approach through a project she and other ethnographers and database developers were involved in with a Māori group to build a digital repository for their taonga (ancestral treasures that might include a variety of things from songs to objects). Taonga are uncommon when compared to modern Euro-American standards insofar as they are "objects" that, similar to Wiener's heirlooms, are themselves person-like agents. We stress the word personlike to clue the reader in to the commoning work performed by previous iterations of ethnographic translation, where taonga was rendered common by making it equivalent to (albeit not exactly the same as) an entity/ concept familiar to Euro-Americans (that is, a person). This translation was taken by the ethnographers and developers involved in the digital repository project as the common ground shared with Māori participants, and upon which the whole group could discuss how the repository would work in relating different entities (various taonga and humans, for example). However, the problems encountered in advancing the work made it evident that for Māori, what made a thing taonga was not a quality intrinsic to it but rather the quality of its relationships. Moreover, the notion of relations at stake was not as straightforward as it would seem. For Māori participants, relations precede and constitute entities rather than the other way around. As Salmon points out, "the uncommonness of these things in relation to the conceptual repertoire of both anthropology and digital technology [was] productive, in this case generating an imperative for methodological innovation" that eventually translated into the refurbishing of both those conceptual repertoires and of how taonga is composed. Indeed, now ethnographers have a "new" understanding of "relations," upon which database developers can base an appropriate digital architecture, and, based on the notion that relations precede entities, the digital repository can generate taonga in ways that did not exist before.

What Salmond's narrative depicts is the movement whereby ethnography alters what it studies while at the same time being transformed itself. This is done through what Viveiros de Castro (2004) calls "translation as controlled equivocation." In contrast with the usual expectation that translation should strive to establish equivalence between two terms through a common referent, translation as controlled equivocation strives not to lose from sight that the terms are different, the difference being an effect of the comparison, of uncommoning. Thus, rather than settling on the "commonality" achieved through a translation, the ethnographer is advised as to its contingent character; the translation works as long as the relation holds the two terms together. Viveiros de Castro $(2004,5)$ provides a vivid image to grasp how this translation works, stating that speaking of translation as controlled equivocation is tantamount to speaking of walking as controlled falling. Both translation and walking work as long as they are constantly reiterated. In Salmon's example, we see this dynamic in the successive "mutual re-description" of taonga and its ethnographic renderings in such a way that they become alter to themselves (that is, what they were in a previous iteration) but never equivalent to each other. Of course, for this to work, both terms have 
to make themselves open to be transformed in the relation.

The cases discussed by our contributors show that commoning often rests on equivocations that disavow uncommonalities, thereby entrenching asymmetries between the elements of the commons. In such situations, uncommoning - patterned after translation as controlled equivocation - might assist commoning in living up to its democratic and equalitarian promise by keeping those involved alert to the uncommons that undergird the commons; calling attention to the asymmetries that translation as uncontrolled equivocation might conceal; creating awareness of the contingent and pragmatic nature of the workability of a translation as controlled equivocation; and committing to mutual transformation (re-description) without having sameness or equivalence as final horizon. To paraphrase Helen Verran (2013), a commons thus constituted will paradoxically involve learning to refuse the colonising reduction to a shared category, and accepting that we (those involved in commoning) may not be metaphysically committed to a common world but rather to going on together in divergence.

Mario Blaser, Department of Geography, Memorial University, St.John's, NL.Email:mblaser@mun.ca.

Marisol de la Cadena, Department of Anthropology, University of California, Davis, CA.

Email:mdelac@ucdavis.edu.

\section{Notes}

1 The articles are part of a larger set of presentations to the Sawyer-Mellon seminar on the uncommons, organised by the guest editors at the University of California, Davis, in May 2015. The editors want to thank participants who did not have papers for this issue but whose input during conversations were key to developing the ideas presented here. They are Tim Choy, Giovanni da Col, Joe Dummit, Cristiana Giordano, Kregg Hetherington, Marie McDonald, Laura Ogden, Dimitris Papadopoulos, Maria Puig de la Bellacasa and Suzana Sawyer. And, of course, thanks to our constant co-thinker, Arturo Escobar.

2 We stress that this is the situation nowadays. One wonders what would happen if possessions and hauntings proliferated to the point that, even if only for $\mathrm{PR}$ reasons, it might be convenient for the tourist industry to do something about it.

\section{References}

Acosta, Alberto. 2010. El Buen Vivir en el camino del postdesarrollo: Una lectura desde la Constitución de Montecristi, Policy Paper 9. Quito, Ecuador: Fundación.

Blaser, Mario. 2013a. "Notes towards a Political Ontology of 'Environmental' Conflicts.” In Contested Ecologies: Nature and Knowledge, ed. Lesley Green, 13-27. Cape Town: HSRC Press. 2013b. "Ontological Conflicts and the Stories of Peoples In Spite of Europe: Towards a Conversation on Political Ontology." Current Anthropology 54(5): 547-568. http:// dx.doi.org/10.1086/672270.

Bollier, David, and Silke Helfrich, eds. 2014. The Wealth of the Commons: A World beyond Market and State. Amherst, MA: Levellers Press.

- , eds. 2015. Patterns of Commoning. Amherst, MA: The Commons Strategy Group/Off the Commons Books.

Burchardt, Hans-Jürgen, and Kristina Dietz. 2014. "(Neo-) Extractivism - A New Challenge for Development Theory from Latin America." Third World Quarterly 35(3): 468486. http://dx.doi.org/10.1080/01436597.2014.893488.

de la Cadena, Marisol. 2010. "Indigenous Cosmopolitics in the Andes: Conceptual Reflections beyond 'Politics." Cultural Anthropology 25(2): 334-370. http://dx.doi.org/10.1111/ j.1548-1360.2010.01061.x.

- 2015. Earth Beings: Ecologies of Practice across Andean Worlds. Durham, NC: Duke University Press. http:/ dx.doi.org/10.1215/9780822375265.

Federici, Silvia. 2014. "Feminism and the Politics of the Commons." In The Wealth of the Commons: A World beyond Market and State, ed. David Bollier and Silke Helfrich, 206-247. Amherst, MA: Levellers Press.

Fennell, Lee Anne. 2011. "Ostrom's Law: Property Rights in the Commons." International Journal of the Commons 5(1): 9-27. http://dx.doi.org/10.18352/ijc.252.

Gudynas, Eduardo. 2011. "Más allá del nuevo extractivismo: Transiciones sostenibles y alternativas al desarrollo" [Beyond new extractivism: sustainable transitions and alternatives to development]. In El desarrollo en cuestión: Reflexiones desde América Latina [Development in Question: Reflections from Latin America], ed. Fernanda Wanderley, 379-410. La Paz, Bolivia: Oxfam and CIDESUMSA.

Harvey, David. 2011. "The Future of the Commons." Radical History Review 2011(109): 101-107. http://dx.doi.org/ 10.1215/01636545-2010-017.

Law, John. 2015. "What's Wrong with a One-World World?" Distinktion: Scandinavian Journal of Social Theory 16(1): 126-139. http://dx.doi.org/10.1080/1600910X.2015.1020066.

Linebaugh, Peter. 2008. The Magna Carta Manifesto: Liberties and Commons for All. Berkeley: University of California Press.

Marshall, Graham. 2007. "Nesting, Subsidiarity, and Community-Based Environmental Governance beyond the Local Scale." International Journal of the Commons 2(1): 75-97. http://dx.doi.org/10.18352/ijc.50.

Ostrom, Elinor. 2009. "Design Principles of Robust Property Rights Institutions: What Have We Learned?" In Property Rights and Land Policies, ed. G.K. Ingram and Y.-H. Hong, 25-51. Cambridge, MA: Lincoln Institute of Land Policy.

—. 2015. Governing the Commons. Cambridge: Cambridge University Press. http://dx.doi.org/10.1017/ CBO9781316423936.

Papadopoulos, Dimitris. 2010. "Insurgent Posthumanism.” Ephemera: Theory and Politics in Organization 10(2): 134-151.

Stengers, Isabelle. 2005. "Introductory Notes on an Ecology of Practices.” Cultural Studies Review 11(1): 183-196. http:/ dx.doi.org/10.5130/csr.v11i1.3459. 
Strathern, Marilyn, M.R. Crick, Richard Fardon, Elvin Hatch, I.C. Jarvie, Rix Pinxten, Paul Rabinow, Elizabeth Tonkin, Stephen A. Tyler, and George E. Marcus. 1987. "Out of Context: The Persuasive Fictions of Anthropology." Current Anthropology 28(3): 251-281. http://dx.doi.org/ 10.1086/203527.

Svampa, Maristella. 2015. "Commodities Consensus: Neoextractivism and Enclosure of the Commons in Latin America." South Atlantic Quarterly 114(1): 65-82. http:// dx.doi.org/10.1215/00382876-2831290.
Verran, Helen. 2013. "Engagements between Disparate Knowledge Traditions: Toward Doing Difference Generatively and in Good Faith." In Contested Ecologies: Dialogues in the South on Nature and Knowledge, ed. Lesley Green, 141-161. Cape Town: HSRC Press.

Viveiros de Castro, Eduardo. 2004. "Perspectival Anthropology and the Method of Controlled Equivocation." Tipiti: Journal of the Society for the Anthropology of Lowland South America 2(1): 3-22. 